\title{
RAZA E IDENTIDAD NACIONAL DE COSTA RICA EN EL PERIÓDICO EL COSTARRICENSE (1846-1849, 1870 Y 1873-1877) ${ }^{1}$
}

\author{
RACE AND NATIONAL IDENTITY IN COSTA RICA IN EL \\ COSTARRICENSE NEWSPAPER (1846-1849, 1870 Y 1873-1877)
}

Chester Urbina Gaitán*

\begin{abstract}
RESUMEN
Los discursos emitidos sobre las características étnico-culturales del costarricense por parte del periódico El Costarricense entre 1846 a 1849, giraron alrededor de la identidad blanca, pacífica y laboriosa de los mismos. En los últimos años de circulación de este periódico, los intelectuales y funcionarios del gobierno del General Tomás Guardia que escribían en este, agregaron a los fundamentos de la identidad nacional, el carácter educado del costarricense. La importancia de este periódico radica en que constituye el primer medio de comunicación donde se divulga tanto a nivel nacional como internacional, las características étnico-culturales de los costarricenses y se consignan textos fundacionales sobre la identidad nacional durante más de tres décadas.
\end{abstract}

PALABRAS CLAVE: COSTA RICA * PUBLICACIONES * HISTORIA * IDENTIDAD * CULTURA * RAZA

\begin{abstract}
The speeches expressed on the ethno-cultural characteristics of Costa Rican by the newspaper El Costarricense from 1846 to 1849, were referred around the white, peaceful and industrious of them. In last years of circulation of this newspaper, intellectuals and government officials of General Tomas Guardia who wrote it, added the character educated of Costa Rican's fundament of national identity. The importance of this newspaper is that it is the first media reports, in which is disclose national and international ethno-cultural characteristics of Costa Ricans and it is recognized foundational texts about national identity for more than three decades.
\end{abstract}

KEYWORDS: COSTA RICA * PUBLICATIONS * HISTORY * IDENTITY *CULTURE * RACE

$\overline{1}$ El autor agradece los comentarios a una versión preliminar del texto al Dr. Rafael Cuevas Molina.

* Universidad Politécnica de Nicaragua (UPOLI).

chesterurbina@yahoo.com 


\section{INTRODUCCION}

Según Juan Carlos Solórzano, en Costa Rica la asimilación de la idea de "homogeneidad" y "blanqueamiento" entre los diversos grupos étnicos fue factible debido a que durante la colonia los habitantes ladinos "...constituían ya más del $50 \%$ del total de la población en el pequeño ecúmene colonizado del área central al iniciarse el siglo XVIII" (Solórzano, 1992). Asimismo, Eugenia Rodríguez concluye que en el marco de un crecimiento demográfico constante especialmente desde 1750 se “... tendió a propiciar la homogeneización étnica caracterizada por el predominio de la población mestiza, asentada especialmente en el Valle Central, mientras que la población aborigen y mulata se ubicó más en las zonas periféricas, en particular en Talamanca y Guanacaste" (1992: 160).

Esta realidad étnica permitió que luego de la independencia se orientara la conformación del proceso de integración socio-cultural de los grupos subalternos, quienes al enfatizar su blanquitud, buscaban su asimilación con el grupo dominante. La idea de "homogeneidad" fue factible debido a que en el pequeño territorio del Valle Central, los mestizos eran el grupo predominante mientras que las otras poblaciones aborigen y mulata se localizaban en su periferia (Gudmundson, 1986: 311; Bozzoli, Ibarra y Quesada, 1998; Soto, 2008). Según Dachner (1996) la élite costarricense del período federal elaboró una imagen de su comunidad política inmersa en un espacio geopolítico más amplio, el territorio de la República Federal; sin embargo, la imagen de lo costarricense se crea en contrapunto con el resto de la comunidad federal. Lo costarricense llegó a asociarse al trabajo, la paz, la homogeneidad étnica y el respeto al régimen de derecho, atributos que se percibieron como rasgos particulares de Costa Rica y las referencias obligadas para diferenciar al "nosotros" de los "otros". Por otra parte, el resto de Centroamérica aparece como una comunidad multiétnica asediada por la guerra civil (Dachner, 1996: 122).

Víctor Hugo Acuña ha señalado que desde los primeros años de vida independiente en el país, ha existido un discurso que exalta que la población costarricense contaba con una serie de virtudes ejemplares como la tranquilidad, la neutralidad, el progreso, el pacifismo, un espíritu de negociación, un carácter industrioso y laborioso, así como, un pueblo compuesto por propietarios (Acuña, 2002:191-228).Este mismo autor también ha indicado que a finales del siglo XIX, la elite política nacional no tenía claridad en su concepto de nación. En 1873, Tomás Guardia propugnaba la formación de América Latina como una sola nacionalidad (Piel y Taracena, 1995: 68). Al respecto, Molina (1995) ha señalado una publicación de Víctor Hugo Acuña titulada: "Comunidad política e identidad política en Costa Rica en el siglo XIX", en el sentido que los testimonios que presenta proceden de viajeros y no de miembros de las elites locales, con lo cual señala la necesidad de investigar más profundamente el contexto social y cultural en que las elites elaboraron $y$ difundieron sus discursos $y$ en particular, las complejas relaciones que tenían con los sectores populares (Molina, 2002). Con base en los señalamientos de Molina es que el presente artículo pretende estudiar los discursos emitidos en la prensa escrita del siglo XIX por gobernantes, intelectuales y miembros de los sectores populares sobre la identidad nacional costarricense.

Por su parte, Steven Palmer ha señalado que el discurso nacional de la época de Tomás Guardia no se preocupó por la cuestión de la raza. Seguía reflejando la concepción utilitaria de la nación de liberalismo del siglo XIX. Para ello, cuestiones de raza, idioma, costumbre y cultura eran cosas pragmáticas, no esenciales ni definitorias: la nación era una unidad social $y$ unos recursos, los cuales por medio de una política y una economía liberal, realizarían el progreso (Piel y Taracena, 1995: 76). Pese a que el nacionalismo configurado alrededor de la figura de Guardia fracasó con la bancarrota del Estado y la entrega del ferrocarril al Atlántico a la United Fruit Company en 1884, entre los intelectuales costarricenses existía la idea sobre la raza nacional conformada por los "elementos protonacionales" antes indicados. No obstante, el aporte de Palmer no aborda los discursos periodísticos, de intelectuales y de funcionarios del gobierno de Tomás Guardia sobre las características del ser costarricense, 
particularidades que venían de varias décadas atrás, pero que en la época de Guardia se le añade el epíteto de educados.

El análisis hacia la singularidad de Costa Rica se comienza a manifestar en las crónicas de viajeros extranjeros que pasaron por el país en el siglo XIX. El bachiller Rafael Francisco Osejo exaltaba en 1834, la estabilidad política y la permanencia del sistema constitucional de gobierno. Acerca de los habitantes decía que eran "pacíficos y laboriosos" (Zelaya, 1971: 80). Otros extranjeros señalaban que "la mayor prosperidad y espíritu de empresa" de Costa Rica en relación con el resto de Centroamérica, radicaba en la supuesta "homogeneidad" racial de los costarricenses, al tener mayor proporción de sangre española con menos mezcla de negro e indio (Fernández, 1972: 113 y 285).

En 1853, los doctores Wagner Moritz y Karl Scherzer acotaban que en Costa Rica existía la diferenciación y la discriminación social (Wagner y Scherzer, 1974). Por otro lado, Anthony Throllope resaltaba las ventajas climáticas del país y la indolencia del costarricense (Fernández, 1972: 472). Para 1899, Máximo Soto Hall denunciaba el carácter extranjerizante de la elite costarricense (Soto, 1992). A pesar de las críticas hechas por los extranjeros, la clase política dominante $y$ los intelectuales al servicio del Estado solo conservaron la parte exaltiva e idílica del país.

Según Iván Molina existen tres interpretaciones acerca del origen de la identidad nacional costarricense. La primera plantea que esa identidad tuvo su origen durante la colonia $y$ fue resultado de un proceso natural, caracterizado por las relaciones cotidianas entre los pobladores en un espacio determinado. Este razonamiento se encuentra contenido en las primeras obras históricas publicadas en el país y luego reproducida en estudios filosóficos y sociológicos, asimismo, fue recuperada no hace mucho tiempo por algunos historiadores profesionales, entre ellos Juan Rafael Quesada.

La segunda explicación que surge a inicios de la década de 1990, refiere que la identidad nacional fue más bien una invención —en el sentido de construcción cultural- de los círculos de políticos e intelectuales liberales que dominaban el Estado costarricense a mediados de la década de 1880. Esta intelligentsia inventó esa identidad a partir de la recuperación de la Campaña Nacional de 1856-1857. El canadiense Steven Palmer fue el que presentó este tipo de razonamiento. La tercera apreciación fue expuesta poco tiempo después por Víctor Hugo Acuña. Para este historiador desde antes de la independencia, las elites locales iniciaron un proceso de invención de particularidades identitarias para diferenciar a Costa Rica del resto de sus vecinos centroamericanos, el cual se intensificó luego de 1821. Por otro lado, Acuña y Quesada señalan que el origen de la identidad nacional se encuentra en el período colonial y que se fue consolidando a largo plazo; sin embargo, para Quesada, esa identidad es un producto natural; mientras que para Acuña -igual que para Palmer - es una invención. Contrario a lo anterior, en cuanto al tiempo histórico de construcción de la identidad nacional, Palmer señala que ocurrió a corto plazo (Molina, 2007: 201).

Este artículo se inserta dentro de esta discusión al señalar que la construcción de la identidad nacional es una invención que se articuló a largo plazo, principalmente durante el período del Dr. José María Castro Madriz (18461849) y del General Tomás Guardia (1870-1882), ya que en estos años se crearon imágenes discursivas importantes sobre la identidad nacional, que serán retomadas en la década de los años 80 del siglo XIX para la construcción cultural de la nación (Molina y Díaz, 2008: 274).

Fundamentado en todo lo anterior, es que el presente artículo tiene como objetivo estudiar los discursos periodísticos de los gobernantes, intelectuales y funcionarios públicos de los gobiernos antes mencionados sobre las características étnico-culturales que se le atribuyeron a los costarricenses y los discursos de los sectores populares sobre su identidad cultural. Para este fin se utilizó el periódico El Costarricense en sus años de circulación, es decir entre 1846 1849, 1870 y 1873-1877. La utilización de este periódico se debe a que constituye el primer medio de comunicación donde se divulga tanto a nivel nacional como internacional, las características étnico-culturales de los costarricenses, 
debido a que en este se consignan textos fundacionales sobre la identidad nacional durante más de tres décadas, lo que permite ahondar en el proceso de construcción, transmisión y asimilación de este tipo de identidad.

\section{LA REPRESENTACIÓN ÉTNICO-CULTURAL DE COSTA RICA EN EL COSTARRICENSE}

El 14 de noviembre de 1846 salía a la luz El Costarricense como semanario oficial publicado por la imprenta del Estado, el cual estuvo a cargo del Dr. Nazario Toledo (18071887), director de la Imprenta Nacional. Incluía artículos, editorial, acuerdos, notas de gobierno, noticias extranjeras, entradas y salidas de barcos, entre otros (El Costarricense, 14/11/1846: 1).Con respecto al Dr. Toledo, se conoce que vino al país proveniente de Guatemala en 1835, fue Presidente de la Asamblea Constituyente de 1846, Ministro Plenipotenciario de Costa Rica en Guatemala en 1849, docente en la Casa de Enseñanza de Santo Tomás, Rector y profesor en la Universidad de Santo Tomás y Ministro de Instrucción Pública en 1858, entre otras funciones públicas (González, 1921). Además, fue admirador del iluminismo francés, del liberalismo $y$ del progresismo (Salazar, 2003: 13) y a fines de 1859, regresó definitivamente a Guatemala.

Para el 28 de noviembre de 1846, El Costarricense publicaba un editorial en el cual se analizaba las características étnico-culturales de Costa Rica:

Colonos españoles i[sicaborigenos [sic] descendientes del Quiché constituyeron en CA la masa primordial a que se añadió una corta porción de Africanos que sirvió de levadura para preparar el fermento.-Concluyamos pues, en primer lugar, que el núcleo, de nuestra sociedad no fue homogéneo". [Además agrega]: "Felizmente en Costa-rica[sic], todos se interesan en el orden, el pueblo es pacífico, i [sic] un buen sentido dirige sus pasos i [sic] exigencias (El Costarricense, 28/11/1846: 9).

De la cita anterior resalta el hecho de que la composición étnica de la sociedad costarricense no es homogénea. Es un pueblo amante del orden político; pacífico y sensato, lo que entraña una estrategia de orden civilizatorio. Este discurso no difiere mucho de los emitidos por viajeros años atrás y tiene como objetivo ocultar la división jerárquica y la existencia de fuerzas disgregadoras que obstaculizaban la constitución de un poder central (Vega, 1981: 51 y Calderón, 1993). Sobre esto último, existe un comentario que apunta que el costarricense es: "un pueblo deseoso de mejoras i[sic] cuyos naturales $\mathrm{i}[\mathrm{sic}]$ vecinos quieren ser todos propietarios, un pueblo naturalmente inclinado al orden, siempre ofrecerá una masa compacta donde se estrellen los proyectos de división..." (El Costarricense, 5/12/1846: 13). El 15 de diciembre de 1846, el Dr. José María Castro Madriz — quien durante la administración de Francisco María Oreamuno fungió como Ministro de Gobernación y Relaciones Interiores y Exteriores, así como Vicejefe de Estado (18461847) - en la revisión general que efectuó a las milicias del Departamento de Heredia, les comunicó lo siguiente:

Soldados, sois padres de familia, sois todos propietarios, sois honrados, sois ciudadanos, en una palabra: sois costarricenses, i[sic] con este dulce titulo empuñais[sic] esas armas solo por sostener el Gobierno que habeis[sic] creado para vuestro bien, i[sic] defender los derechos del suelo, de este suelo predilecto en que nacierais (El Costarricense, 19/12/1846: 22).

Lo señalado por este mandatario constituye un discurso constitucional del ser costarricense, donde se le atribuyen cualidades como las de padre de familia, propietario, honrado $y$ ciudadano. Esta caracterización pretende que el costarricense perciba cuáles son sus vínculos primordiales y la creencia en un parentesco de sangre. Esta identificación se da dentro del ámbito de la conformación de una identidad étnica en un grupo de parentesco ampliado, está sustentada sobre "elementos protonacionales" que son usados para generar la fuerza coercitiva del deber moral de solidaridad del costarricense para con los miembros de su colectividad y la fuerza 
emocional que produce el simbolismo de los vínculos de sangre y de familia (Isaacs, 1975).

La Nación se construye sobre el modelo de la "comunidad étnica". Para Anderson esto se fundamenta sobre el sentimiento de una "camaradería horizontal" fundada en "mitos fraternales" (2000: 4-7). Según H. Isaacs, la familia es la comunidad primordial por excelencia a cuya imagen $y$ semejanza se construyen comunidades más amplias, como los grupos étnicos, los grupos emigrados y la misma nación (Isaacs, 1975). Fundamentado en todo lo anterior, es que se matiza la idea planteada por Ronald Soto de que entre 1821 y 1880, los gobernantes e intelectuales costarricenses no dieron importancia al aspecto de la etnicidad (Soto, 2010).

Con respecto a los "elementos protonacionales", se comparte la definición de Eric J. Hobsbawn en cuanto a que son una serie de atributos que son valorados como específicos y distintivos de una colectividad humana, entre ellos se puede citar cualidades más o menos objetivas como: la lengua, un determinado grupo étnico, la religión, un territorio y régimen constitucional compartido. También existen características subjetivas como: una historia o mitología comunes, una cultura, entre otras. Estas características, sean solas o combinadas, son expuestas como los elementos distintivos de la nación y parte fundamental de la identidad de sus miembros (Hobsbawm, 1992: 46-79).

La primera administración del Dr. Castro Madriz contribuyó con la conformación de la imaginería de una comunidad política de tipo nacional, al aprobar el 31 de agosto de 1848, el surgimiento de Costa Rica como República, con lo cual se decretó el 15 de setiembre como fiesta nacional y permitió la creación de una bandera, un escudo y una moneda (Díaz, 2005). Según se ha comprobado, este mandatario puso las bases para la construcción de una identidad nacional al concebirla como "una familia plenamente extendida" (Connor, 1994).

A diferencia de lo descrito en 1846 sobre la heterogeneidad étnica del costarricense, para mediados de 1847 , se ofrece otra opinión $y$ se resalta que en el país las poblaciones están concentradas en una extensión de pocas leguas, compuestas de pocos habitantes de conformación homogénea (El Costarricense, 07/08/1847: 154). En la visita que hizo el Jefe de Estado, Dr. José María Castro Madriz, a la ciudad de Cartago a finales de agosto de 1847 , algunos miembros de los sectores populares de ese lugar le dedicaron algunos versos, resaltando los siguientes:

\section{"Sencillos labradores \\ De la nevada sierra \\ Venid con vuestras flores, I[sic] ofreced las espigas \\ Con que brinda la tierra \\ Un premio a las fatigas".}

"Sin paz vuestras praderas

Desiertas se hallarían

I[sic] los mansos ganados que apacentan [sic]En los bosques ocultos vagarian[sic] In quietos[sic] también, i[sic] sin amparo Vosotros tirarías el arado" (El Costarricense, 04/09/1847: 170).

Como se observó en estos versos, los poetas populares -así llamados por el periódico en estudio- expresaron su posición en la jerarquía de clase como trabajadores agrícolas: sencillos labradores que se satisfacen con el ofrecimiento de sus productos $y$ amantes de la paz, la cual les asegura el trabajo cotidiano. Esto concuerda con lo señalado por Oliva y Quesada sobre la poesía popular costarricense en el siglo XIX, lo cual se encuentra mayoritariamente formada por poemas no críticos, básicamente contemplativos (1997: 20). Sin embargo, en los versos de estos poetas populares citadinos del Valle Central, es notoria su auto identificación como trabajadores y pacíficos.

A inicios de 1848, un articulista que usaba el pseudónimo "EE", acotaba que en Costa Rica vivían más de cien mil habitantes, todos dedicados a la industria agrícola, fabril y mercantil, todos eran propietarios y poseían principios de moral sin los cuales no pueden existir las sociedades (El Costarricense, 22/01/1848). En setiembre de este año, se señala que la población de Costa Rica es homogénea, todos son blancos, todos hablan castellano, todos tienen iguales costumbres y todas 
las poblaciones con excepción de Guanacaste y Puntarenas, están ubicadas a doce leguas de distancia (El Costarricense, 30 /09/1848: 521).

Hacia finales de enero de 1849 , en el país circulaban las ideas socialistas y se le enseña al lector que en la sociedad costarricense no podían arraigarse: "aunque felizmente no aparece en nuestro suelo la horrible fisonomía del comunismo, ni puede aparecer donde la propiedad está bien dividida, i[sic] donde las costumbres están en guardia contra el abordaje de las malas pasiones,..." (El Costarricense, 27/01/1849: 65). En contraposición a esta opinión, el 10 de febrero de 1849 , se explica que Costa Rica debe sus progresos al soplo benéfico del socialismo (El Costarricense, 10/02/1849: 77).La primera cita constituye una de las primeras referencias al comunismo en el país, donde esta corriente ideológica no podía asentarse en la sociedad nacional debido a la "igualdad" en la distribución de la tierra y a las costumbres de tipo conservadoras, principalmente católicas. Esta referencia hace alusión al comunismo de Robert Owen quien se destacó por la aplicación práctica de métodos de gestión que aumentaron la productividad de la empresa y el bienestar de sus trabajadores, al brindarles mejoras en áreas como vivienda, condiciones higiénicas, educación, prohibición del trabajo infantil, mejoras salariales y fijación de una cantidad máxima de horas de trabajo (Santos, 2002: 97-124).

En la segunda referencia, el término socialismo está asociado a igualitarismo social, el cual no existió en la época colonial, ya que existieron la esclavitud y la explotación (Quirós, 1996). Sin embargo, la diferenciación social no fue tan marcada como en otras colonias del imperio español, donde surgió una aristocracia terrateniente (Fonseca, 1989: 309 y Gudmundson, 1990). En ambas citas se trata de mantener el sentido de igualdad de los costarricenses. Sobre la circulación de libros que contenían las ideas socialistas y comunistas en el país durante la primera mitad del siglo XIX, Molina solo ha señalado las temáticas existentes en la biblioteca de Rafael Francisco Osejo de 1828, de los libros comprados por Edward Wallerstein en 1844 y las obras traídas por Vicente Aguilar y Nazario Toledo en 1851 (Molina, 1995: 76-82). Pese a esto, no se conoce acerca de los títulos de los libros ni los autores de los mismos, además, estos conjuntos de libros no eran los únicos que existían en Costa Rica. El estudio de Molina se basa en fuentes diversas, dispersas y fragmentarias, que le dan un carácter incompleto, como él mismo lo señala (Molina, 1995: 14).

Los discursos emitidos sobre la identidad nacional costarricense, tanto por el periódico en estudio como por el Dr. Castro Madriz y los "poetas populares" cartagineses, se dieron dentro del marco urbano del Valle Central, núcleo geográfico a partir del cual se propagara la identidad blanca de los costarricenses. Para Acuña, esto se explica por el temprano consentimiento al interior de los grupos políticos y el temprano éxito de la economía cafetalera, factores que posibilitaron la afirmación de una conciencia regional en el Valle Central que posterior a 1870, se extenderá entre las clases populares como la base del nacionalismo costarricense (2002: 218). Asimismo, pese a la existencia del sentimiento localista, las elites políticas de las ciudades principales del Valle Central costarricense compartían una cierta imagen común sobre su comunidad política y sobre su Estado, lo cual pudo mantenerse debido a la calma política que vivía el país (Díaz, 2005: 8).

En 1870, con la llegada al poder del General Tomás Guardia Gutiérrez, los militares asumen la dirección del Estado. Durante sus mandatos se deshizo de la influencia de la oligarquía cafetalera en el poder político, con lo que obtuvo estabilidad. Para esto tuvo que despolitizar y reorganizar el ejército. Además, fomentó el desarrollo burocrático del Estado y la construcción de obras públicas, principalmente la del ferrocarril al Atlántico (Díaz, 2005: 44-45). Este mismo año, el periódico El Costarricense amplia su circulación fuera del país debido a que contaba con los siguientes agentes en Nicaragua: Pedro Alvarado (León), Eduardo Montiel (Granada) y Octaviano Cantón (Rivas). A nivel nacional disponía de los siguientes agentes: D.F. Cazorla (Alajuela), Francisco Sáenz (Cartago), Juan V. Gutiérrez (Heredia), Juan V. Marchena (Puntarenas) e Inocente Barrios (Liberia). En 1874, 
el periódico circulaba países como Guatemala, El Salvador, Honduras, Nicaragua y Panamá. Asimismo, en las ciudades de Cartagena, Bogotá, Medellín, Popayán Socorro, Barranquilla, Guayaquil, Lima, El Havre, Londres, Paris y Bruselas. Para 1873, el redactor responsable era el colombiano Uladislao Durán M., quien establece el periódico en estudio con el fin de apoyar la obra de Tomás Guardia. En 1875, le sucede el Lic. Francisco Chaves Castro, quien fungió como Subsecretario de Gobernación del gobernante antes mencionado. El último redactor responsable fue el intelectual colombiano Joaquín Pablo Posada, quien tuvo el cargo en 1876. Según se puede comprobar, todas estas personas fueron políticos, comerciantes y directores de periódicos destacados que aconsejaron política e ideológicamente al Presidente Guardia .

Para el 28 de octubre de 1874, El Costarricense señala que el adelanto intelectual y material que Costa Rica ha logrado, se debe a su paz permanente que asegura el trabajo y asimismo, la propiedad. El pueblo costarricense no era revolucionario, porque nada tiene que aspirar por la vía de los trastornos públicos: ser pasivo dispuesto al trabajo y a la obediencia a las autoridades constituidas, si alguna se vez se presta a ser instrumento para trastornar el orden, es merced a la sugestión y al engaño. Asimismo, acota que todas las conquistas del país en la vía del progreso se debía a tres condiciones: paz, educación y trabajo (El Costarricense, 28/10/1874: 2). El carácter apologético de esta cita debe enterderse en el sentido de que fue hasta la segunda década del siglo Xx, la clase dominante costarricense brindó mayor apoyo económico al ejército, que a la educación (Palacios y Rojas, 1992).

El periódico antes citado agrega que los costarricenses son católicos sin fanatismo, caritativos y hospitalarios (El Costarricense, 15/10/1875: 2). También apunta que Costa Rica no ha pasado por guerras internas $y$ períodos de inestabilidad política debido a que poseía dos características distintivas: la unidad de raza y la riqueza del pueblo (El Costarricense, 23/12/1875: 1).

El 29 de octubre de 1875, en el artículo "El Costarricense" se explica cuales eran las características culturales que los salvaron de la anarquía $y$ de las revoluciones que azotaron a los demás países centroamericanos, luego de la caída de la República Federal de Centroamérica:

... ciertas circunstancias especiales de Costa Rica, cuales son la homogeneidad de su población, el carácter naturalmente industrioso y pacífico de sus habitantes y a los hábitos de orden y de obediencia que han caracterizado al pueblo. Esas circunstancias siempre nos hubieran favorecido aún permaneciendo unidos en cuerpo de Nación con los otros Estados (ibid, 29/10/1875: 1).

Esta referencia comprueba lo señalado por Acuña (2002), en cuanto que hasta 1848, en el imaginario político costarricense, la Nación era Centroamérica y la patria Costa Rica. Además, incluye que las propias élites plantearon el espectro de la identidad nacional centroamericana sobre la imagen recién inventada de la Nación costarricense (Piel y Taracena, 1995). Según se ha evidenciado, desde mediados del siglo XIX, elementos culturales como la homogeneidad étnica, el carácter industrioso, trabajador, pacífico y de sumisión política que se pueden considerar como "elementos protonacionales", han sido utilizados por la élite protonacional costarricense para diferenciarse de los demás países centroamericanos (Hroch, 1985 y Molina, 2005: 111).

El abogado y político cubano Ramón de Céspedes Fornaris (1808-1890), en su artículo escrito en Cartago, el 29 de mayo de 1876, titulado: "Los descalzos", acotaba que el arquetipo del costarricense era el "descalzo" - el campesino-que asistía a la escuela a sus lecciones de la mañana, a las cuales agregaban las muy elocuentes de la industria y del comercio. Los descalzos tenían unidad de raza, eran blancos y de un tipo varonil. Para Céspedes, la uniformidad del color de la raza era importante, debido a que las razas heterogéneas se oponen a todo progreso; mientras que los elementos cuando no se pueden amalgamar solo sirven para contribuir a la división y a la anarquía, la cual es señalada como la carcoma más destructora de la felicidad común, es decir, los descalzos eran la democracia (02/06/1876: 2). Por último, el 1 de febrero de 
1877, en El Costarricense se señala sobre la raza nacional costarricense, lo siguiente:

Costa Rica es un país pequeño, es cierto, en población, pero la raza que lo puebla es vigorosa: no existe aquí, sino en una parte muy diminuta, insignificante, de la raza aborigenes [sic]: la aristocracia, en su sentido más odioso, ha sido desconocida: la esclavitud, es decir, el germen de la raza africana no ha existido tampoco, gracias a la indiferencia, al olvido, podríamos decir, que la metrópoli hizo de este precioso rincón del Mundo de Colon (ibid, 01/02/1877: 1).

Las publicaciones del periódico en estudio, las cuales se referían a la conformación étnica de la sociedad costarricense y las características culturales que supuestamente tenían los costarricenses, influyeron en el Mensaje Presidencial de Tomas Guardia de 1877 al resaltar que en Costa Rica existía una "población homogénea" de "propietarios en mayor o menor escala" y una ausencia de intereses opuestos. En 1880, señala que en Costa Rica hay más maestros que soldados (Piel y Taracena; 1995). Contrario a lo señalado en 1846, donde se resalta la herencia africana del costarricense, en la cita anterior esta se oculta. Con respecto a los grupos aborígenes, estos se ponen en vías de extinción, lo que comprueba el señalamiento de Soto en cuanto a que desaparecer por completo la imagen en Costa Rica era difícil, así que la táctica de los intelectuales fue ubicarla temporalmente en el pasado, mientras que los indígenas vivos eran vistos como ajenos a la nación, sin conexión con ella y en vías de desaparición (Soto, 1998: 41-52).

\section{CONCLUSIÓN}

Los discursos emitidos sobre las características étnico-culturales del costarricense por parte del periódico El Costarricense, entre 1846 y 1849, se estructuraron alrededor de su identidad blanca, pacífica y laboriosa. Estas características se pudieron mantener debido al consenso de las elites políticas y a la estabilidad en que se desenvolvía el país. Para 1846, el Dr. José María Castro Madriz elaboró un discurso en el que pone las bases para la construcción de la identidad nacional, al insertarla dentro del ámbito de la conformación de una identidad étnica en un grupo de parentesco ampliado. En 1847, algunos "poetas populares cartagineses" expresaron su auto identificación cultural como trabajadores y pacíficos dentro de un discurso acrítico y contemplativo.

En el análisis del periódico, se encontraron dos referencias al término comunismo, —el de Robert Owen-quien explica que esta corriente ideológica no podía asentarse en la sociedad nacional debido a la "igualdad" en la distribución de la tierra y a las costumbres de tipo conservadoras, principalmente católicas. En la segunda referencia, el término socialismo está asociado a igualitarismo social, el cual no existió en la época colonial, ya que se daba la esclavitud y la explotación. Con esto se trató de mantener el sentido de igualdad de los costarricenses.

En los últimos años de circulación de El Costarricense, se tiene que este periódico aumentó su circulación a nivel nacional e internacional, lo que fue aprovechado por los intelectuales $y$ funcionarios del gobierno del General Tomás Guardia que escribían en este para añadir a los fundamentos de la identidad nacional, el carácter educado del costarricense. Contrario a lo señalado en 1846, donde se resalta la herencia africana del costarricense, en 1877 el periódico antes mencionado la oculta, $y$ así pone a los grupos aborígenes del país en vías de extinción, con el fin de consolidar la imagen de la raza blanca como la predominante. Fundamentado en todo lo anterior, se afirma que la identidad nacional costarricense se fue conformando a largo plazo, lo que se comprueba con el hecho de que durante los años de circulación de El Costarricensese se fueron creando imágenes discursivas fundacionales sobre las características étnico-culturales de los costarricenses y sobre la identidad nacional, que serán retomadas en la década de los años 80 del siglo XIX, con el fin de la construcción cultural de la nación. 
BIBLIOGRAFÍA

LIBROS

Anderson, Benedict. Imagined communities. Lóndres, Inglaterra-Nueva York, EEuU: VERSO, 2000.

Bozzoli, María Eugenia; Ibarra, Eugenia y Quesada, Juan Rafael. 12 de octubre, Día de las Culturas. Costa Rica pluricultural. San José, Costa Rica: Editorial de la Universidad de Costa Rica, 1998.

Connor, Walter. Ethno-nationalism. The quest for understanding. New Jersey, EEUU: Princeton University Press, 1994.

Fonseca, Elizabeth. Costa Rica colonial. La tierra y el hombre. San José, Costa Rica: Editorial Universidad CentroamericanaEDUCA, 1989.

González, Luis Felipe. Historia de la influencia extranjera en el desenvolvimiento educacional y científico de Costa Rica. San José, Costa Rica: Imprenta Nacional, 1921.

Gudmundson, Lowell. Costa Rica antes del café. San José, Costa Rica: Editorial Costa Rica, 1990.

Hobsbawm, Eric. Naciones y nacionalismo desde 1780. Barcelona, España: Editorial Crítica, 1992.

Hroch, Miroslaw. Social preconditions of national revival in Europe. Nueva York, EEUU: Cambridge University Press, 1985.

Isaacs, Harold R. Idols of the tribe, group identity and political change. Nueva York, EEUU: Harper \& Row Publishers, 1975.

Isaacs, Harold R. Costarricense por dicha: identidad nacional y cambio cultural en Costa Rica durante los siglos XIX y $X X$. San José, Costa Rica: Editorial de la Universidad de Costa Rica, 2005.

Molina Jiménez, Iván. El que quiera divertirse. Libros y sociedad en Costa Rica, 17501914. San José, Costa Rica: Editorial de la Universidad de Costa Rica, 1995.

Molina Jiménez, Iván y Díaz Arias, David. La Campaña Nacional (1856-1857): historiografía, literatura y memoria. San José, Costa Rica: Editorial de la Universidad de Costa Rica, 2008.
Oliva Medina, Mario y Quesada Monge, Rodrigo. "Cien años de poesía popular en Costa Rica (1850-1950)”. Héroes y pueblo por escrito en el siglo XIX. Tomo I. San José, Costa Rica: Editorial de la Universidad Estatal a Distancia-EUNED, 1997.

Piel, Jean y Taracena A., Arturo (comp.). Identidades nacionales y Estado moderno en Centroamérica. San José, Costa Rica: Editorial de la Universidad de Costa Rica, 1995.

Quirós, Claudia. La era de la encomienda. San José, Costa Rica: Editorial de la Universidad de Costa Rica, 1996.

Salazar Mora, Jorge Mario. Historia de la educación costarricense. San José, Costa Rica: EUCR, 2003.

Soto Hall, Máximo. El Problema. San José, Costa Rica: Editorial de la Universidad de Costa Rica, 1992.

Vega, José Luis. Orden y progreso: la formación del Estado nacional en Costa Rica. San José, Costa Rica: Instituto Centroamericano de Administración Público-ICAP, 1981.

Moritz, Wagner y Scherzer, Carl. La República de Costa Rica en América Central. Tomo I. San José, Costa Rica: Depto. de Publicaciones del Ministerio de Cultura, Juventud y Deportes, 1974.

Zelaya, Chester. El bachiller Osejo. San José, Costa Rica: Editorial Costa Rica, 1971.

Fernández Guardia, Ricardo. Costa Rica en el siglo XIC. Antología de viajeros. San José, Costa Rica: Ediciones Educativas-EDUCA, 1972.

\section{PUBLICACIONES PERIÓDICAS}

Dachner Trujillo, Yolanda. "De la individualidad política a la predestinación singular: Costa Rica en la obra de Osejo, Molina y Peralta". Anuario de Estudios Centroamericanos 22 (2). San José, Costa Rica: Editorial de la Universidad de Costa Rica, 1996.

Díaz Arias, David. "Construcción de un Estado moderno: política, Estado e identidad nacional en Costa Rica, 1821-1914". 
Serie Cuadernos de Historia de las Instituciones de Costa Rica 18. San José, Costa Rica: Editorial de la Universidad de Costa Rica, 2005.

Gudmundson, Lowell. "De "negro" a "blanco" en la Hispanoamérica del siglo xix: la asimilación afroamericana en Argentina y Costa Rica”. Mesoamérica 7(12). Guatemala: Centro de Investigaciones Regionales de Mesoamérica, diciembre, 1986.

Soto Quirós, Ronald. "Desaparecidos de la Nación”: Los indígenas en la construcción de la identidad nacional costarricense 1851-1942". Revista de Ciencias Sociales 82. San José, Costa Rica: Editorial de la Universidad de Costa Rica (EUCR), 1998.

Solórzano, Juan Carlos. "Conquista, colonización y resistencia indígena en Costa Rica”. Revista de Historia 25. Universidad Nacional de Costa Rica, enero-junio, 1992: 191-205.

Rodríguez Sáenz, Eugenia. "Historia de la familia en América Latina: balance de las principales tendencias". Revista de Historia 26. Universidad Nacional de Costa Rica julio-diciembre, 1992: 145-183.

Acuña Ortega, Víctor Hugo. "La invención de la diferencia costarricense, 1810-1870". Revista de Historia 45. San José, Costa Rica: Editorial de la Universidad de Costa Rica, Escuela de Historia-Universidad Nacional de Costa Rica, Centro de Investigaciones Históricas de América Central-Universidad de Costa Rica enerojunio, 2002.

Molina Jiménez, Iván. "Fiesta e identidad. A propósito de un libro de David Díaz Arias”. Revista de Historia 55-56. San José, Costa Rica: Editorial de la Universidad de Costa Rica. Escuela de Historia-Universidad Nacional de Costa Rica, Centro de Investigaciones Históricas de América CentralUniversidad de Costa Rica, enerodiciembre, 2007.
Santos Redondo, Manuel. "Robert Owen, pionero del "management". Sociología del Trabajo. 45. Primavera 2002. España: Siglo XXI de España Editores.

TESIS

Calderón Hernández, Manuel Enrique. "Las fuerzas sociales en la formación del poder político en Costa Rica entre 18211849". [Tesis de Maestría en Sociología]. Universidad de Costa Rica, 1993.

Palacios Robles, María de los Ángeles y Rojas Vargas, Andrea. "Génesis, evolución y papel ideológico de la educación cívica costarricense, 1821-1940". [Tesis de Licenciatura en Historia]. Universidad de Costa Rica, 1992.

Soto Quirós, Ronald. "Representaciones del pueblo costarricense: la «raza» entre la mirada externa y la construcción nacional, 1821-1917". [Tesis doctoral en Estudios Ibéricos e Iberoamericanos"] Francia, Université de Bordeaux 3, 2010.

\section{REVISTAS ELECTRÓNICAS}

Soto Quirós, Ronald. "Imaginando una nación de raza blanca en Costa Rica: 1821-1914" Amérique Latine Histoire et Mémoire. Les Cahiers-ALHIM 15. 2008. EN: <HTTP:// ALHIM.REVUES.ORG/INDEX 2930.HTML> [Consultado El 13 DE ENERO DEL 2012].

Díaz Arias, David. "La invención de las naciones en Centroamérica, 1821-1950". Boletín AFEHC 15. Asociación para el Fomento de los Estudios Históricos en Centroamérica-AFEHC. Diciembre 2005. En: <http://ress.afehc-historiacentroamericana.org/_articles/portada_ afehc_articulos14.PDF> [Consultado el 15 de enero del 2012].

Molina Jiménez, Iván. "Víctor Hugo: comunidad política e identidad política en Costa Rica en el siglo XIX". Revista Bibliográfica de Geografía y Ciencias Sociales. 7 (367). Universidad de Barcelona, España. 2002. En: <http://www.ub.es/geocrit/b3w-367. htm> [Consultado el 17 de enero del 2012]. 


\section{PERIÓDICOS}

El Costarricense. Año 1, nros. 1 y 3. 1er. trimestre. 14 y 28 de noviembre de 1846 .

El Costarricense. Año 1, nros. 4 y 6. 1er. trimestre. 5 y 19 de diciembre de 1846 .

El Costarricense. Año 1, nro. 39. 2ndo. semestre. 7 de agosto de 1847.

El Costarricense. Año 1, nro. 43. 2ndo. semestre. 4 de setiembre de 1847.

El Costarricense. Año 2, nro. 62. 1er. semestre. 22 de enero de 1848.

El Costarricense. Año 2, nro. 95. 2ndo. semestre. 30 de setiembre de 1848.

El Costarricense. Año 3, nro. 9. 1er. semestre. 27 de enero de 1849.

El Costarricense. Año 3, nro. 11. 1er. semestre. 10 de febrero de 1849.
El Costarricense. Nro. 24. Época II. 3er. trimestre. 28 de octubre de 1874.

El Costarricense. Nro. 54. Época II. 4to. trimestre. 15 de octubre de 1875.

El Costarricense. Nro. 56. Época II. 4to. trimestre. 29 de octubre de 1875.

El Costarricense. Nro. 64. Época II. 4to. trimestre. 23 de diciembre de 1875.

de Céspedes Fornaris, Ramón. El Costarricense. Nro. 19. Época III. 2ndo, trimestre. 2 de junio de 1876.

El Costarricense. Nro. 46. Época III. 4to. trimestre. $1^{\circ}$ de febrero de 1877.

Fecha de ingreso: 01/01/2012

Fecha de aprobación: 09/01/2013 
